SANTOS, H.S.; GOTO, R. Enxertia em plantas de pimentão no controle da murcha de fitóftora em ambiente protegido. Horticultura Brasileira, Brasília, v.22, n.1, p. 45-49, jan-mar 2004.

\title{
Enxertia em plantas de pimentão no controle da murcha de fitóftora em ambiente protegido
}

\author{
Haydée S. Santos ; Rumy Goto \\ UNESP-FCA, Departo. Produção Vegetal, C. Postal 237, 18603-970 Botucatu-SP; E-mail: haydee@fca.unesp.br
}

\begin{abstract}
RESUMO
Avaliou-se a viabilidade de utilização da enxertia em plantas de pimentão (Capsicum annuum, L.), visando o controle da murcha de fitóftora. A pesquisa foi conduzida de setembro de 2000 a julho de 2001, na UNESP, Botucatu, em ambiente protegido. Adotou-se o delineamento experimental de blocos ao acaso, com 4 repetições e 5 plantas por parcela. Foram utilizados dois porta-enxertos resistentes a Phytophthora capsici, híbridos F1 de Capsicum annuum, e três híbridos comerciais suscetíveis (Elisa, Margarita e Magali-R). A enxertia foi realizada quando porta-enxertos e enxertos apresentavam respectivamente sete e três folhas verdadeiras, pelo método de garfagem fenda simples. Aos 14 dias após o transplante das mudas foi feita a inoculação do fungo, utilizando sementes de trigo infestadas pelo patógeno, depositadas ao redor do colo da planta. Quatro dias após a inoculação, e a partir daí a cada 15 dias, foram feitas avaliações que confirmaram a resistência dos porta-enxertos e a suscetibilidade das plantas não enxertadas. Observou-se bom nível de compatibilidade de enxertia em todas as combinações, precocidade de florescimento das plantas não enxertadas, manutenção de resistência à doença pelas plantas enxertadas durante todo o período e variações na altura das plantas em algumas combinações. Com relação à produção, verificou-se que os frutos mantiveram as características fenotípicas de cada híbrido, revelando que não houve interferência dos porta-enxertos neste aspecto. Concluiu-se haver viabilidade técnica de utilização da enxertia no controle da murcha de fitóftora em ambiente protegido.
\end{abstract}

Palavras-chave: Solanaceae, Capsicum annuum, L., Phytophthora capsici, Leonian, cultivo protegido.

\begin{abstract}
Sweet pepper grafting to control phytophthora blight under protected cultivation

The viability of grafting was evaluated in sweet pepper (Capsicum annuum, L) plants to control phytophthora blight. The research was carried out during the period of September 2000 to July 2001, in Botucatu (Brazil), under protected cultivation. The experimental design was of randomized blocks with four replication and five plants per plot. Rootstocks resistant to $P$. capsici, $\mathrm{F} 1$ hybrids of $C$. annuum and three susceptible commercial hybrids (Elisa, Margarita and Magali R) were used. The cleft grafting was realized when rootstocks and grafts showed seven and three true leaves, respectively. The inoculation was done 14 days after transplanting the seedlings by depositing wheat seeds infested with the fungus, around the stem of each plant. Evaluations were done each 15 days starting four days after the inoculations. A good level of grafting compatibility in all the combinations, flowering precocity of non grafted plants, maintenance of the resistance to the disease in grafted plants and variations in height of the plants in some combinations were observed. The physiological characteristics of the hybrids were not influenced by the plants used as rootstocks. Grafting could be used as alternative to control phytophthora blight under protect cultivation.
\end{abstract}

Keywords: Solanaceae, Capsicum annuиm, L., Phytophthora capsici, Leonian.

(Recebido para publicação em 09 de agosto de 2002 e aceito em 03 de novembro de 2003)

\begin{abstract}
A enxertia em hortaliças iniciou-se no Japão e na Coréia no final da década de 1920, em melancia (Citrullus lanatus) como medida preventiva contra patógenos de solo (Lee, 1994). Entretanto, somente a partir de 1955 começou a ser praticada mais efetivamente em berinjela, buscando evitar a murcha-defusário (Fusarium oxysporium) (Yamakawa, 1982). No Brasil, acreditase que a enxertia em hortaliças começou a ser realizada comercialmente na década de 80, em cultivo de pepino no estado de São Paulo, visando o controle de nematóides e obtenção de frutos livres de cera (Goto, 2001). Existem relatos de que na Amazônia, em pequenas culturas, a enxertia de tomateiro em jurubeba é
\end{abstract}

uma prática utilizada há muito tempo, para controle da murcha-bacteriana causada por Ralstonia solanacearum.

A cultura do pimentão tem na murcha, causada pelo fungo Phytophthora capsici Leonian, um de seus maiores problemas fitossanitários. Este fungo foi descrito inicialmente no Novo México em 1922 (Leonian, 1922). No Brasil, esta doença foi observada pela primeira vez, em Ribeirão Preto em 1951, dizimando um cultivo dessa solanácea (Amaral, 1952). Atualmente, a doença encontra-se distribuída em quase todos os continentes, em regiões de clima temperado ou tropical. Apenas no continente Australiano ainda não foi relatada sua ocorrência (Irwin et al., 1995).
Os sintomas típicos da doença causada por $P$. capsici em pimentão são a murcha repentina, necrose de coloração marrom-escura no colo e morte da planta. O sistema radicular fica necrosado e apodrecido (Matsuoka e Ansani, 1984).

Diversas medidas de controle têm sido adotadas a fim de impedir que a doença se estabeleça: rotação de culturas, mulching, solarização, manejo da irrigação, controle biológico, através do uso de microorganismos antagônicos, controle genético, com a utilização de cultivares e híbridos resistentes e o controle químico. No entanto, cada um desses métodos tem apresentado limitações, e a busca de alternativas tecnicamente viáveis tem sido constante (Hwang e Kim, 1995). 
Em ambiente protegido, os patógenos de solo representam um desafio ainda maior ao cultivo do pimentão, pois são muito mais agressivos sob condições de alta umidade e temperatura. Sua ocorrência é comum em solos de estufa com problemas de salinização, conduzidos geralmente com manejo inadequado (Vida et al., 1998).

Considerando os fatores acima citados, a enxertia pode ser uma boa alternativa para o controle da murcha de fitóftora em ambiente protegido. A maior dificuldade de adotar a técnica da enxertia em pimentão até agora, era a inexistência de porta-enxertos adequados, que, além de não apresentarem bom nível de compatibilidade, conferiam pouco vigor ao enxerto e transmitiam pungência aos frutos, por serem provenientes de pimentas (Miguel, 1997). Entretanto, este problema está sendo solucionado com a obtenção de híbridos como porta-enxerto, conforme Kobori (1999).

Avaliou-se nesse trabalho dois dos porta-enxertos resistentes à murcha-defitóftora obtidos por Kobori (1999) enxertando-os com três híbridos comerciais suscetíveis, verificando assim o nível de compatibilidade da enxertia e o desempenho produtivo das plantas enxertadas, a resistência dos porta-enxertos e a evolução dos sintomas da doença nas plantas não enxertadas.

\section{MATERIAL E MÉTODOS}

A pesquisa foi conduzida na UNESP em Botucatu, São Paulo, de setembro de 2000 a julho de 2001. As plantas foram conduzidas em ambiente protegido, numa estrutura tipo arco, de 7,0 m de largura por 40,0 m de comprimento, 3,0 $\mathrm{m}$ de pé direito, coberta com filme de polietileno de $100 \mu \mathrm{m}$ de espessura, e sem controle das condições ambientais.

O delineamento experimental foi de blocos ao acaso, com 9 tratamentos e 4 repetições. Os tratamentos resultaram da combinação de dois porta-enxertos, híbridos de Capsicum annuum: AF-2638 (linhagem SCM-334 x linhagem AF1947) e AF-2640 (linhagem SCM-334 $x$ linhagem AF1949) (Sakata Seed Sudamérica) enxertados com 3 híbridos comerciais suscetíveis à Phytophthora capsici: 'Margarita' (Rogers Syngenta Seeds), 'Elisa' (Rogers Syngenta Seeds) e 'Magali-R' (Sakata Seed Sudamérica). Os híbridos suscetíveis foram utilizados também como pés-francos. Cada parcela experimental foi constituída de cinco plantas, espaçadas de 1,4 x 0,4 m, sendo utilizadas nas avaliações as três plantas centrais. Foram realizadas 9 colheitas dos frutos, com no mínimo $50 \%$ de maturação.

A enxertia foi de garfagem fenda simples (Yamakawa, 1982), realizada quando porta-enxertos e enxertos apresentavam, respectivamente, sete e três folhas verdadeiras expandidas. $\mathrm{O}$ ponto de enxertia foi na altura da terceira folha verdadeira do porta-enxerto, quando o caule estava com aproximadamente $3 \mathrm{~mm}$ de diâmetro. A operação de enxertia foi realizada aos 51 dias após a semeadura dos porta-enxertos e 41 dias após a dos enxertos. Constou de um corte transversal do caule do porta-enxerto, seguido da abertura de uma fenda atingindo $3 / 4$ do seu diâmetro a uma profundidade de aproximadamente $1,5 \mathrm{~cm}$. As mudas do enxerto, apresentando três folhas verdadeiras foram cortadas em bisel abaixo das folhas cotiledonares, sendo encaixadas então na fenda do porta-enxerto.

O transplante das mudas ocorreu aos 21 dias após a enxertia. A irrigação foi por gotejamento, com um gotejador por linha de cultura. As plantas foram tutoradas em espaldeira simples, com condução livre em número de hastes. Não se eliminou a primeira flor, e os demais tratos culturais foram feitos conforme as necessidades da cultura.

Aos 35 dias após a enxertia, quando as plantas estavam com nove folhas verdadeiras, foi feita a inoculação do fungo, em todos os tratamentos. O inóculo utilizado foi produzido na UNESP em Botucatu, de acordo com o protocolo citado por Marque et al. (1999). Utilizou-se um isolado de $P$. capsici (PI 15) do grupo A2, proveniente de Bragança Paulista, São Paulo. Foi preparado um substrato orgânico com 50 sementes de trigo em dois frascos Schott Reagent de $500 \mathrm{ml}$ com $100 \mathrm{ml}$ de água destilada que receberam duas autoclavagens a $120^{\circ} \mathrm{C}$ por 30 minutos com um interva- lo de três dias. A seguir foram transferidos para a superfície das sementes três discos de meio ágar-água de 5,0 $\mathrm{mm}$ de diâmetro com crescimento ativo de $P$. capsici. O patógeno foi incubado durante 15 dias a $24^{\circ} \mathrm{C}$ no escuro, agitando-se periodicamente os frascos para facilitar a infestação total das sementes.

A metodologia de inoculação consistiu na deposição de 3 a 5 sementes contaminadas ao redor do colo da planta, saturando-se em seguida o solo com água. Os resultados obtidos com este método são semelhantes aos alcançados quando se utiliza suspensão de zoósporos na concentração de $10^{4}$ zoósporos/ml (Marque et al., 1999).

Para comparar a evolução dos sintomas da doença nos híbridos não enxertados, foram avaliados três modelos matemáticos que possibilitam estabelecer uma relação entre proporção da doença e tempo (Bergamin Filho, 1995). Dentre eles o modelo monomolecular foi o que melhor se ajustou, sendo então utilizado para esta análise.

Aos quatro dias após a inoculação e a partir daí a cada 15 dias, foram feitas as avaliações, nas quais verificou-se a manifestação dos sintomas e severidade da doença, por meio de uma escala de notas assim estipulada: 1- planta sem sintomas; 2- escurecimento do caule; 3 planta murcha; 4- planta morta.

Foram também avaliadas a precocidade de florescimento, expressa pelo número de dias entre a semeadura e a antese, a altura das plantas aos 36 ; 56; 101; 136 e 167 dias após a enxertia e o número de frutos totais e comercializáveis produzidos pelas plantas enxertadas. Foram também analisados o diâmetro, comprimento e espessura da parede dos frutos colhidos.

\section{RESULTADOS E DISCUSSÃO}

O nível de compatibilidade inicial (pegamento da enxertia) é muito importante para que se tenha sucesso na produção de mudas enxertadas. Neste trabalho, obteve-se $93 \%$, equivalente ao que foi alcançado em pimentão por Choe (1989).

As plantas enxertadas mantiveramse sem sintomas da doença durante todo o período de condução do experimento. 
As não enxertadas manifestaram os sintomas de maneira diferenciada (Figura 1). Na comparação dos híbridos, verificou-se que 'Magali-R' apresentou menor proporção de plantas doentes aos quatro dias após a inoculação (DAI), enquanto 'Margarita' e 'Elisa' estiveram com proporções muito próximas. Aos 41 DAI, houve uma acentuada evolução dos sintomas nas plantas do híbrido Elisa, que manteve esta tendência até o final das avaliações. Foi possível a partir daí observar que cada híbrido tem um comportamento próprio quanto à evolução da doença, no entanto, como esperado, todos a desenvolveram.

A precocidade de florescimento foi verificada, por ser um dos métodos utilizados para classificar o pimentão em precoce ou tardio, conforme Melo (1997). Esta análise não objetivou uma comparação entre os híbridos, visto que cada um possui características próprias, mas observar se os porta-enxertos, nas diferentes combinações, induziriam mudanças significativas nesse aspecto, o que não ocorreu (Tabela 1). Observouse apenas que o híbrido Elisa tendeu a uma precocidade de florescimento quando enxertado em AF-2640. Quanto aos pés francos, chegaram à antese da primeira flor cerca de 12 dias antes das plantas enxertadas. Este comportamento foi também observado em plantas de pepino (Cañizares, 1997), e é previsto tendo em vista o estresse de enxertia que as plantas sofreram. Rachow-Brandt e Kolmann (1992) observaram que somente cinco a sete dias após a enxertia iniciou-se o transporte de assimilados, o que vem atrasar a fase de desenvolvimento vegetativo que deve existir antes do início do florescimento.

Observou-se variações significativas na altura das plantas, dependendo do porta-enxerto utilizado (Tabela 2). Observa-se que nas combinações de 'Magali-R' com os dois porta-enxertos, a partir dos 136 DAE o porta-enxerto AF2638 conferiu maior altura às plantas, entretanto não diferiu significativamente de AF-2640. O híbrido Elisa durante o período de 36 aos 101 dias apresentou plantas de maior altura quando enxertado em AF-2640 e aos 136 e 167 dias manteve esta tendência. $O$ híbrido Margarita não mostrou diferença signi-

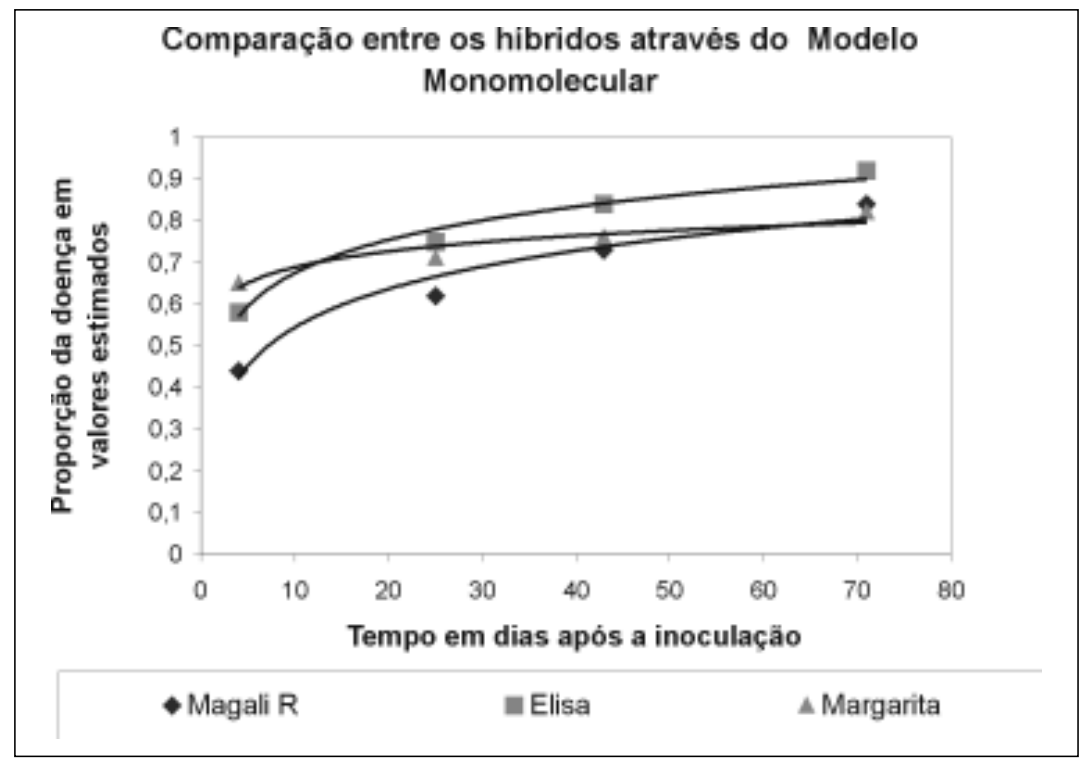

Figura 1. Evolução dos sintomas da doença nos híbridos x tempo em dias após a inoculação. São Manuel, UNESP, 2000.

Tabela 1. Médias do número de dias da semeadura até a antese. São Manuel, UNESP, 2000.

\begin{tabular}{lc}
\hline \multicolumn{1}{c}{ Tratamentos } & Antese \\
\cline { 2 - 2 } & Dias a partir da semeadura' \\
\hline 'Magali R' & $73,95 \mathrm{~cd}^{2}$ \\
AF-26383 x 'Magali-R' & $84,95 \mathrm{a}$ \\
AF-26403 x 'Magali-R' & $85,80 \mathrm{a}$ \\
'Elisa'4 & $69,45 \mathrm{~d}$ \\
AF-2638 x 'Elisa' & $82,00 \mathrm{ab}$ \\
AF-2640 x 'Elisa' & $77,65 \mathrm{bc}$ \\
'Margarita'4 & $70,80 \mathrm{~d}$ \\
AF-2638 x 'Margarita' & $82,20 \mathrm{ab}$ \\
AF-2640 x 'Margarita' & $81,05 \mathrm{ab}$ \\
\hline Média & 78,65 \\
\hline DMS (Tukey 5\%) & 5,66 \\
\hline CV (\%) & 2,99 \\
\hline
\end{tabular}

${ }^{1}$ Dados originais (média de 5 plantas em 4 repetições); ${ }^{2}$ Colunas seguidas pelas mesmas letras não diferem estatisticamente entre si pelo teste de Tukey a 5\%; ${ }^{3}$ Porta-enxerto; ${ }^{4}$ Pé franco

ficativa com a variação do porta-enxerto. Kobori (1999) relatou que o híbrido 'Magali-R' não apresentou diferença em altura quando enxertado nos mesmos porta-enxertos usados neste trabalho, entretanto observou que as plantas enxertadas ficaram menores em relação aos pés-francos. Esta comparação não foi feita neste caso, pois as plantas não enxertadas morreram após a contaminação do fungo. É possível que a menor altura das plantas tenha sido influencia- da pelos porta-enxertos, por terem a linhagem Serrano Criollo de Morellos334 como um de seus progenitores, ou por alguma exigência não conhecida no manejo das irrigações e fertilizações. A questão nutricional das plantas de pimentão enxertadas deverá ser objeto de novos estudos, visto que a enxertia pode produzir alterações na absorção e transporte de nutrientes, o que está diretamente correlacionado com o crescimento da planta. 
Tabela 2. Médias das alturas das plantas de pimentão em centímetros ${ }^{1}$, aos 36; 56; 101; 136 e 167 dias após a enxertia (DAE). São Manuel, UNESP, 2000.

\begin{tabular}{lcccccc}
\hline \multirow{2}{*}{ Porta-enxerto x enxerto } & \multicolumn{5}{c}{ Altura das plantas (cm) } \\
\cline { 2 - 7 } & $\mathbf{3 6}$ & $\mathbf{5 6}$ & $\mathbf{1 0 1}$ & $\mathbf{1 3 6}$ & $\mathbf{1 6 7}$ \\
\hline AF-2638 x 'Magali-R' & $29.830 \mathrm{a}^{\mathbf{2}}$ & $57.913 \mathrm{a}$ & $\mathbf{7 6 . 6 6 3 \mathrm { a }}$ & $\mathbf{8 9 . 9 9 5} \mathrm{a}$ & $113.745 \mathrm{a}$ \\
AF-2640 x 'Magali-R' & $26.745 \mathrm{ab}$ & $53.663 \mathrm{a}$ & $75.828 \mathrm{a}$ & $83.830 \mathrm{ab}$ & $105.830 \mathrm{ab}$ \\
AF-2638 x 'Elisa' & $19.748 \mathrm{c}$ & $43.245 \mathrm{c}$ & $55.415 \mathrm{c}$ & $65.248 \mathrm{~b}$ & $78.750 \mathrm{c}$ \\
AF-2640 x 'Elisa' & $29.205 \mathrm{a}$ & $52.495 \mathrm{ab}$ & $69.413 \mathrm{ab}$ & $\mathbf{7 3 . 4 9 8} \mathrm{ab}$ & $98.498 \mathrm{abc}$ \\
AF-2638 x 'Margarita' & $23.203 \mathrm{bc}$ & $44.333 \mathrm{c}$ & $53.080 \mathrm{c}$ & $68.083 \mathrm{~b}$ & $82.498 \mathrm{bc}$ \\
AF-2640 x 'Margarita' & $26.748 \mathrm{ab}$ & $46.583 \mathrm{bc}$ & $56.498 \mathrm{bc}$ & $65.665 \mathrm{~b}$ & $83.163 \mathrm{bc}$ \\
\hline Média & 25,91 & 49,70 & 64,48 & 74,38 & 93,74 \\
\hline DMS (Tukey 5\%) & 4,76 & 6,78 & 13,25 & 18,80 & 23,37 \\
\hline CV (\%) & 7,80 & 5,94 & 8,04 & 11,00 & 10,85 \\
\hline
\end{tabular}

${ }^{1}$ Dados originais (média de três plantas em quatro repetições); ${ }^{2}$ Colunas seguidas pelas mesmas letras não diferem estatisticamente entre si pelo teste de Tukey a $5 \%$

Tabela 3. Médias do número e peso dos frutos totais (FT), comercializáveis (FC), diâmetro (D), comprimento (CO) e espessura da parede (EP) de frutos de pimentão obtidos em nove colheitas (95, 121, 134, 141, 148, 204, 218, 231, 247 DAE). São Manuel, UNESP, 2001.

\begin{tabular}{|c|c|c|c|c|c|c|c|}
\hline \multirow{2}{*}{$\begin{array}{c}\text { Porta-enxerto } x \\
\text { enxerto }\end{array}$} & \multicolumn{2}{|c|}{ Número de frutos ${ }^{1}$} & \multicolumn{2}{|c|}{ Peso dos frutos $\left(g^{1}\right)$} & \multirow{2}{*}{$D\left(\mathrm{~cm}^{1}\right)$} & \multirow{2}{*}{$\mathrm{CO}\left(\mathrm{cm}^{1}\right)$} & \multirow{2}{*}{$\mathrm{EP}\left(\mathbf{m m}^{1}\right)$} \\
\hline & FT & FC & FT & FC & & & \\
\hline AF-2638 x 'Magali-R' & 14,25 a & $13,33 a$ & $123,55 \mathrm{a}$ & $126,42 \mathrm{~b}$ & $6,21 b^{2}$ & $12,48 \mathrm{a}$ & $4,96 \mathrm{~b}$ \\
\hline AF-2640 x 'Magali-R' & $12,25 \mathrm{a}$ & $11,08 \mathrm{a}$ & $133,41 \mathrm{a}$ & $137,51 \mathrm{ab}$ & $6,02 \mathrm{~b}$ & $11,96 a b$ & $5,01 \mathrm{~b}$ \\
\hline AF-2638 x 'Elisa' & 10,66 a & 9,83 a & 152,86 a & $156,67 a b$ & $7,35 \mathrm{a}$ & $9,85 \mathrm{c}$ & $6,19 a$ \\
\hline AF-2640 x 'Elisa' & $10,91 \mathrm{a}$ & $9,75 a$ & $152,94 \mathrm{a}$ & 159,76 a & 7,18 a & $10,18 \mathrm{bc}$ & $5,96 \mathrm{a}$ \\
\hline AF-2638 x 'Margarita' & $11,07 \mathrm{a}$ & $10,25 \mathrm{a}$ & 144,29 a & $148,99 a b$ & $6,82 a b$ & $11,13 a b c$ & $5,42 \mathrm{ab}$ \\
\hline AF-2640 x 'Margarita' & 11,83 a & $11,08 \mathrm{a}$ & $151,29 \mathrm{a}$ & $156,09 \mathrm{ab}$ & $7,26 \mathrm{a}$ & $10,87 \mathrm{abc}$ & $5,56 \mathrm{ab}$ \\
\hline Média & 11,83 & 10,88 & 143,05 & 147,57 & 6,81 & 11,08 & 5,52 \\
\hline DMS (Tukey 5\%) & 7,18 & 6,05 & 35,37 & 32,94 & 0,83 & 1,86 & 0,87 \\
\hline CV (\%) & 26,41 & 24,19 & 10,76 & 9,72 & 5,29 & 7,30 & 6,90 \\
\hline
\end{tabular}

${ }^{1}$ Dados originais (média da produção de 3 plantas em 4 repetições e 9 colheitas); ${ }^{2}$ Colunas seguidas pelas mesmas letras não diferem estatisticamente entre si pelo teste de Tukey a $5 \%$

Verificou-se uma diferença significativa na média do peso dos frutos comercializáveis para a combinação AF$2640 \mathrm{x}$ 'Elisa', que foram os de maior peso (Tabela 3). O híbrido Margarita não apresentou diferença em número e peso dos frutos com a variação dos porta-enxertos, e 'Magali-R' tendeu a produzir frutos comerciáveis de menor peso em combinação com AF-2638. Pode-se notar que em todas as combinações em que se utilizou o porta-enxerto AF-2640, observou-se uma tendência de produção de frutos comercializáveis de maior peso.

Observando-se o número e o peso médio de frutos por planta pode-se concluir que os porta-enxertos não reduziram o vigor dos híbridos enxertados, um dos maiores problemas apresentados pelos porta-enxertos usados em pimentão na Europa até o presente momento (Miguel, 1997). Por outro lado, estudos realizados com estes híbridos em condições de ambiente protegido, sem enxertia, apresentaram produções equivalentes às que foram obtidas neste trabalho (Melo, 1997; Kobori, 1999; Cunha et al., 2001).

Conclui-se que existe viabilidade técnica de utilização da enxertia em plantas de pimentão conduzidas em ambiente protegido, como alternativa de controle da murcha causada por $P$. capsici. Foi comprovada também a tolerância destes mesmos porta-enxertos a Meloidogyne incognita, Raça 2 (Santos et al., 2002), o que torna sua utilização ainda mais interessante. O presente estudo não se deteve na questão econômica, no entanto, considerando a facilidade de produção das mudas enxertadas, que não requereram nenhum investimento a mais em instalações, treinamento especial do enxertador, além de terem apresentado alto índice de pegamento da enxertia, acredita-se que a relação custo-benefício seja positiva na decisão por adotar esta forma de controle dos patógenos de solo citados.

\section{LITERATURA CITADA}

AMARAL, J.F. Requeima do pimentão. $O$ Biológico, São Paulo, n.18, p.160-161, 1952.

BERGAMIN FILHO, A. Curvas de progresso da doença. In: BERGAMIN FILHO, A. KIMATI, H. AMORIM L. (Ed). Manual de fitopatologia. 3.ed. São Paulo. Agronômica Ceres, 1995, p.602-26. 
CAÑIZARES, K.A.L. Efeito da enxertia de dois hibridos de pepino (Cucumis sativus) e dois hibridos de abóbora (Cucurbita sp) sob ambiente protegido. Botucatu, FCA, 1997. 73 p. (Tese mestrado)

CHOE, J.S. Phytophthora blight of green pepper in Korea. Extension Bulletin-Aspac, Food Fertil. Technol. Cent., n. 302, p.18-25, 1989.

CUNHA, A.R.; ESCOBEDO, J.F.; KLOSOWSKI, E.S.; GALVANI, E. Características de produtividade e classificação de frutos de pimentão híbrido Elisa em condições de ambiente protegido e de campo. Horticultura Brasileira, Brasília, v. 19, suplemento CD-ROM, 2001.

GOTO, R. Qualidade e produção de frutos de pepino japonês em função dos métodos de enxertia. Botucatu: FCA, 2001. 60 p. (Tese livre docência)

HWANG, B.K.; KIM, C.H. Phytophothora blight of pepper and its control in Korea. Plant Disease, v.79, p.221-7, 1995

IRWIN, A.G.; IRWIN, A.C.; CAHILL, D.M.; DRENTH, A. Phytophthora in Australia. Australian Journal of Agricultural Research, n.46, p.1311-1337, 1995.
KOBORI, R.F. Controle da Murcha de Fitóftora (Phytophthora capsici) em pimentão (Capsicum annuum, L.) através da enxertia. Botucatu: FCA, 1999. 138 p. (Tese doutorado)

LEONIAN, L.H. Stem and fruit blight of peppers caused by Phytophthora capsici sp. nov. Phytopathology, v. 12, p. 401-8, 1922.

MARQUE, J.M.; SOUZA, N.L.; KOBORI, R.F.

Novo processo de inoculação de Phytophthora capsici em pimentão. Fitopatologia Brasileira, v.24, suplemento, p.336, 1999.

MATSUOKA, K.; ANSANI, C.V. Doenças fúngicas de pimentão e pimenta. Informe Agropecuário, Belo Horizonte, v.10, n.113, p.45-8, 1984.

MELO, A.M.T. Análise Genética de caracteres de fruto em hibridos de pimentão. Piracicaba, ESALQ, 1997. 112p. (Tese doutorado)

MIGUEL, A.G. Injerto de hortalizas. Valencia: Generalitat Valenciana, 1997. 88 p. (Divulgación técnica, 40).

RACHOW-BRANDT, G.; KOLLMANN, R. Studies on graft unions. IV. Assimilate transport and sieve element restitution in homo and heterografts. Journal of Plant Physiology,v.139, p.579-583, 1992.
SANTOS, H.S.; WILCKEN, S.R.S.; GOTO, R. Reprodução de Meloidogyne incognita, Raça $2 \mathrm{em}$ diferentes porta-enxertos de pimentão. Nematologia Brasileira, v.26, n.2, p.209-211, 2002.

VIDA, J.B.; KUROZAWA, C.; ESTRADA, K.R.F.S; SANTOS, H.S. Manejo fitossanitário em cultivo protegido. In: GOTO, R.; TIVELLI, S.W. (Org). Produção de hortaliças em ambiente protegido: condições subtropicais. São Paulo: Editora UNESP, 1998. p.58-104.

YAMAKAWA, K. Use of rootstocks in solanaceous fruit vegetable production in Japan. Japanese Agricultural Research, v.15, n.3, p.175$9,1982$. 